\title{
ATTEMPTS TO APPLY THE DIRECT SIRE COMPARISON TO THE FLECKVIEH POPULATION IN BADEN-WüRTTEMBERG
}

\section{U. JAUdAS. - Institut für Tierhaltung und Tierzüchtung der Universität Hohenheim D-700o Stuttgart, 70 BRD.}

Since several assumptions of the herdmate comparison, which is the current method for sire evaluation, are no longer valid, besides other improvements attempts are made to use the " direct sire comparison" as proposed by Henderson. On account of the small herd size all lactations are used and the records are adjusted for age and month of calving. The sires are grouped according to their date of birth in order to account for genetic trend. For computation of sire effects and group effects mixed-model equations are formed where the herd equations are absorbed into sire equations. Accounting for relationship among sires is possible. The equations are solved iterative and the sire proofs are computed by twice the sum of sire effect plus the corresponding group effect. For the computational procedures a Fortran program has been written.

\section{ESTIMATION OF AGE CORRECTION FACTORS \\ OF THE FLECKVIEH POPULATION IN BADEN-WürtTEMBERG}

\section{R. BuchsteINER. - Institut für Tierhaltung und Tierzüchtung der Universität Hohenheim D-70oo Stuttgart 70, BRD.}

In the first part, the current age correction method, employed in Baden-Württemberg is presented. By this method, it is assumed that there are no gedetical differences between lactations and that the age influence within lactation on lactation yield can be neglected.

In the second part age correction factors are calculated with three different on the models basis of 87 roo lactations from registered Fleckvieh cows. Model I conforms to the gross Comparison (GC) method, model 2 and 3 conform to the maximum likelihood (ML) method. GC factors are biased, because of selection and genetic trend. ML factors possess the properties of unbiasedness and minimum variance; they are based upon both intra-cow and inter-cow information.

The constants for lactations are presented in a table. They indicate that the bias in the Gross factors is rather small.

The age effects within first and second lactation on lactation yield are significant and cannot be neglected in the future,

The interactions between calcing seasons and lactations are not important.

They indicate however, that older cows are more severely affacted by summer calving than are heifers.

\section{The Modified cumulative Difference}

R. Bar-Anan. - Department of Animal Husbandry, Ministry of Agriculture Hahirya, Tel Aviv, Israel.

The method adopted in Israel of estimating breeding values has been described. In sire evaluations, the first three lactations and the length of the calving interval are taken into account and the effects of the sires of the herdmates and of the dams are evaluated. Contemporary Comparisons for calf mortality, for growth rate of sons and for conformation of daughters, days open and dry, yield persistency and daughter disposal rate are computed. In cow evaluations the effects of the sires of the cow and of the herdmates are taken into account.

\section{COMBINED INDEX FOR MILK PRODUCTION \\ AND GROWTH RATE AS SELECTION CRITERIA OF PERFORMANCE TESTED AI BULLS}

L. Elofson, B. Danell, Philipsson, Department of Animal Breeding, Agricultural College S-75o o7 Uppsala 7, Sweden.

The reliability of a pedigree index for milk production was checked in a comparison with the progeny test indexes of 206 bulls. The correlation was found to be $0.4 \mathrm{r}$, which is in acceptable agreement with the theoretically expected value. 